\title{
Empirical Polarity Parameters for Hexaalkylguanidinium-based Room-temperature Ionic Liquids
}

\author{
Milen G. Bogdanov ${ }^{\mathrm{a}, \mathrm{c}}$, Ivan Svinyarov ${ }^{\mathrm{a}}$, Helene Kunkel ${ }^{\mathrm{b}}$, Christine Steinle $^{\mathrm{b}}$, \\ Maria Arkhipova ${ }^{\mathrm{b}}$, Willi Kantlehner ${ }^{\mathrm{c}}$, and Gerhard Maas ${ }^{\mathrm{b}}$ \\ ${ }^{a}$ Faculty of Chemistry, University of Sofia, 1, J. Bourchier Blvd., 1164 Sofia, Bulgaria \\ ${ }^{\mathrm{b}}$ Institute of Organic Chemistry I, University of Ulm, Albert-Einstein-Allee 11, $89081 \mathrm{Ulm}$, \\ Germany \\ ${ }^{c}$ Fakultät Chemie/Organische Chemie, Hochschule Aalen, Beethovenstraße 1, 73430 Aalen, \\ Germany
}

Reprint requests to Prof. Dr. G. Maas. Fax: +49 731 5022803. E-mail: gerhard.maas@uni-ulm.de

Z. Naturforsch. 2010, 65b, 791-797; received March 31, 2010

The polarity of a series of 36 hexaalkylguanidinium-based room-temperature ionic liquids (RTILs), featuring different unbranched alkyl substituents in the cation and eight different anions, has been determined by means of Reichardt's solvatochromic betaine dye; $E_{\mathrm{T}}(30)$ and the corresponding normalized $E_{\mathrm{T}}^{\mathrm{N}}$ values are presented. The positively solvatochromic probe 5dimethylamino- $5^{\prime}$-nitro-2,2' -bithiophene was used to characterize unspecific solvent/solute interactions (effects of dipolarity/polarizability) of ten hexaalkylguanidinium and, for comparison, two 1alkyl-3-methylimidazolium ionic liquids.

Key words: Ionic Liquids, Polarity, Hexaalkylguanidinium Salts, Reichardt's Dye, 5-Dimethylamino-5'-nitro-2,2'-bithiophene

\section{Introduction}

In the past two decades, ionic liquids (ILs) have been in the focus of many research groups worldwide. A particular combination of properties, such as negligible vapor pressure, nonflammability, good thermal stability, low chemical reactivity, a large electrochemical window, high ionic conductivity, and tunable miscibility with other common solvents qualifies certain types of ionic liquids for diverse fields of application. Ionic liquids have been introduced as novel solvents in synthesis [1] including catalysis [2], as electrolytes in electrochemistry [3], as constituents of dye-sensitized solar cells [4], and as materials for separation technology and analytical chemistry [5,6], to name just a few.

Ionic liquids consist entirely of ions, and the so far best investigated and most widely used ILs contain charge-stabilized organic cations with an imidazolium, ammonium, pyrrolidinium, pyridinium, and phosphonium core; physico-chemical properties of many members of these substance families have been compiled and discussed [1,6-8]. Surprisingly, guanidiniumbased ionic liquids have only recently emerged on the scene, in spite of the fact that the excellent stabilization of the positive charge and the low chemical reactivity of hexaalkylguanidinium ions have been known for a long time; for selected references to the synthesis and physico-chemical properties of hexaalkylguanidiniumbased ionic liquids, see the literature [7,9-16].

Ionic liquids which are liquid at room temperature (RTILs) have a potential to replace traditional organic solvents in synthetic work, and the viability of this concept has been proven in recent years for a variety of synthetic transformations [1,2]. Solvent polarity, i.e., the overall solvation capability for solutes [17], is an important criterion for choosing the appropriate solvent for a particular chemical reaction. Several polarity scales are known in the literature, most of which are based on the interaction of solvatochromic dyes with a solvent [18]. The most widely accepted scales are Reichardt's $E_{\mathrm{T}}(30)$ and the corresponding normalized $E_{\mathrm{T}}^{\mathrm{N}}$ scale [19] as well as the Kamlet-Taft $\pi^{*}$ scale [20]. For many RTILs based on the abovementioned organic cations, $E_{\mathrm{T}}(30)[21,22]$ and $\pi^{*}$ $[6 a, 22,23]$ values have already been determined. We report herein empirical polarity data for a wide range of hexaalkylguanidinium-based RTILs with different anions. 


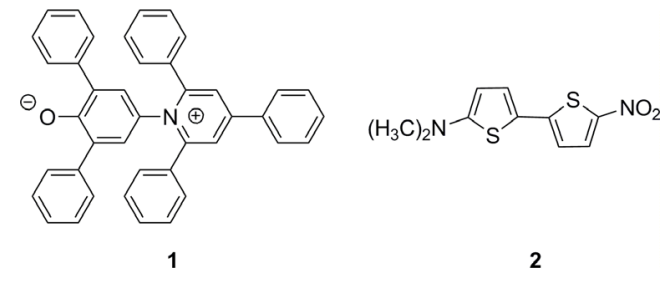

Fig. 1. Solvatochromic dyes used in this study.

\section{Results and Discussion}

For the determination of empirical polarity data, we considered solvent/solute interactions of hexaalkylguanidinium-based RTILs with two solvatochromic dyes, namely Reichardt's betaine dye $\mathbf{1}$ [19] and the merocyanine-like bithiophene $\mathbf{2}$ developed by Effenberger and Würthner [24] (see also lit. [25]) (Fig. 1). While the most intense long-wavelength absorption of $\mathbf{1}$, resulting from an intramolecular charge transfer (CT), is shifted to shorter wavelength with increasing solvent polarity, the opposite trend is observed for $\mathbf{2}$ (negative and positive solvatochromism, respectively). The solvatochromic behavior of $\mathbf{1}$ is influenced to a considerable extent by specific interactions of the phenoxide oxygen atom with the solvent, in particular via hydrogen bonding. In contrast, the solvatochromism of bithiophene 2 results almost exclusively from unspecific solvation interactions caused by the effects of dipolarity and polarizability of the solvent, and is therefore applicable to all types of solvents [24b]. In line with these different properties, the solvation behavior of $\mathbf{2}$ gives a poor correlation with the $E_{\mathrm{T}}$ polarity scale based on $\mathbf{1}$, but a good correlation with the $\pi^{*}$ (dipolarity/polarizability) values developed by Kamlet and Taft.

The values of the solvent polarity scale $E_{\mathrm{T}}(30)$ are defined [19] as the molar transition energies of betaine dye $\mathbf{1}$ (no. 30 in the original publication) at standard conditions $\left(25^{\circ} \mathrm{C}\right.$ and $1 \mathrm{bar}$ ) according to Eq. 1 , where $\lambda_{\max }$ is the maximum-absorption wavelength of the solvatochromic CT band. The dimensionless normalized $E_{\mathrm{T}}^{\mathrm{N}}$ scale was introduced later, using water $\left(E_{\mathrm{T}}^{\mathrm{N}}=\right.$ $1.00)$ and TMS $\left(E_{\mathrm{T}}^{\mathrm{N}}=0.00\right)$ as polar and non-polar reference solvents, respectively, giving rise to Eq. 2 .

$$
\begin{aligned}
& E_{\mathrm{T}}(30)\left(\mathrm{kcal} \mathrm{mol}^{-1}\right)=28591 / \lambda_{\max }(\mathrm{nm}) \\
& E_{\mathrm{T}}^{\mathrm{N}}=\left(E_{\mathrm{T} \text { solvent }}-30.7\right) / 32.4
\end{aligned}
$$

We have determined the $E_{\mathrm{T}}$ and $E_{\mathrm{T}}^{\mathrm{N}}$ values for 36 hexaalkylguanidinium-based ionic liquids, which represent combinations of guanidinium cations differing in the alkyl substituents and eight different anions (Fig. 2 and Table 1). Fig. 3 shows where these hexaalkylguanidinium-ILs appear on the $E_{\mathrm{T}}^{\mathrm{N}}$ scale in relation to sixteen common organic solvents. It is noteworthy that the effect of traces of water on the position of the UV/Vis absorption maxima was found to be small for the ILs under study (see Exerimental Section).

The compounds studied can be divided in two groups. Group 1 (Table 1, entries 1-26) considers the polarity as a function of the chain length of only one variable alkyl substituent in the guanidinium ion on the one hand, and the influence of the anion on the other. In group 2 (Table 1, entries $27-36$ ), three sets of cations, each with three (or four) different anions are compared. The cations differ by the chain lengths of the two alkyl groups at one $\mathrm{NR}_{2}$ function $\left(\left[\mathrm{N}_{11} \mathrm{~N}_{22} \mathrm{~N}_{44}\right] v s\right.$. $\left.\left[\mathrm{N}_{22} \mathrm{~N}_{44} \mathrm{~N}_{66}\right]\right)$ or the replacement of two butyl groups by the more polar 2-methoxyethyl groups ( $\left[\mathrm{N}_{11} \mathrm{~N}_{22} \mathrm{~N}_{44}\right] v s$. [ $\left.\left[\mathrm{N}_{11} \mathrm{~N}_{22} \mathrm{~N}_{2 O 1,2 O 1}\right]\right)$.

As can be seen from Fig. 3, the studied guanidinium RTILs cover a wide polarity range, thereby matching $E_{\mathrm{T}}^{\mathrm{N}}$ values from dipolar non-hydrogen-bond-donating (NHBD) solvents (DMF, DMSO, acetonitrile) up to polar hydrogen-bond-donating (HBD) solvents (primary alcohols, water). Except for the values close to water, this is the typical polarity range for RTILs containing no acidic hydrogen atoms [21]. An interesting aspect appears from the analysis of group $1 \mathrm{com}$ pounds. Except for the tosylate series, which shows a relatively broad range of $E_{\mathrm{T}}^{\mathrm{N}}$ values $\left(\Delta E_{\mathrm{T}}^{\mathrm{N}}=0.22\right)$, the polarity values barely vary with the cation (i.e. the variation of one out of the six alkyl groups), but are distinctly different for the four anions $\mathrm{Cl}^{-}, \mathrm{Sac}^{-}$, $\mathrm{BF}_{4}^{-}$, and $\mathrm{Ace}^{-}$. For ILs with other cations (e. g. 1,3dialkylimidazolium, $N$-alkylpyridinium, tetraalkylammonium), it has been reported [6,21, and lit. cit.] that the polarity change is only marginal when the length of an alkyl chain is modified step by step. If a general trend should be defined, the polarity decreases slightly with increasing length of the alkyl chain R. In the case of the hexaalkylguanidinium ions, the observed consistency can be attributed to the higher mass of the cation-anion combination relative to the mass of the substituent R. Considering the influence of the anion, the chloride series shows the lowest polarity compared to the others (mean value $E_{\mathrm{T}}^{\mathrm{N}}=0.43$ ), which puts the chloride salts into the range of the dipolar NHBD solvents DMSO and DMF. The polarity values increase 
Table 1. Abbreviation, water content, absorption maximum and polarity $\left(E_{\mathrm{T}}(30)\right.$ and $E_{\mathrm{T}}^{\mathrm{N}}$ values $)$ for the ionic liquids evaluated in this study; see Fig. 2 for structural formulae.

\begin{tabular}{|c|c|c|c|c|c|c|c|c|c|c|c|}
\hline Entry & Ionic liquid & $\begin{array}{l}\mathrm{H}_{2} \mathrm{O} \\
(\mathrm{ppm})\end{array}$ & $\begin{array}{l}\lambda_{\max }{ }^{a} \\
(\mathrm{~nm})\end{array}$ & $\begin{array}{c}E_{\mathrm{T}}(30) \\
\left(\mathrm{kcal} \mathrm{mol}^{-1}\right)\end{array}$ & $E_{\mathrm{T}}^{\mathrm{N}}$ & Entry & Ionic liquid & $\begin{array}{l}\mathrm{H}_{2} \mathrm{O} \\
(\mathrm{ppm})\end{array}$ & $\begin{array}{l}\lambda_{\max }{ }^{a} \\
(\mathrm{~nm})\end{array}$ & $\begin{array}{c}E_{\mathrm{T}}(30) \\
\left(\mathrm{kcal} \mathrm{mol}^{-1}\right)\end{array}$ & $\overline{E_{\mathrm{T}}^{\mathrm{N}}}$ \\
\hline 1 & {$\left[\mathrm{~N}_{22} \mathrm{~N}_{33} \mathrm{~N}_{63}\right] \mathrm{Cl}$} & 670 & 638 & 44.8 & 0.44 & 2 & {$\left[\mathrm{~N}_{22} \mathrm{~N}_{33} \mathrm{~N}_{64}\right] \mathrm{Cl}$} & 690 & 646 & 44.3 & 0.42 \\
\hline 3 & {$\left[\mathrm{~N}_{22} \mathrm{~N}_{33} \mathrm{~N}_{66}\right] \mathrm{Cl}$} & 690 & 651 & 43.9 & 0.41 & 4 & {$\left[\mathrm{~N}_{22} \mathrm{~N}_{33} \mathrm{~N}_{68}\right] \mathrm{Cl}$} & 720 & 638 & 44.8 & 0.44 \\
\hline 5 & {$\left[\mathrm{~N}_{22} \mathrm{~N}_{33} \mathrm{~N}_{610}\right] \mathrm{Cl}$} & 600 & 641 & 44.6 & 0.43 & 6 & {$\left[\mathrm{~N}_{22} \mathrm{~N}_{33} \mathrm{~N}_{63}\right] \mathrm{BF}_{4}$} & 370 & 559 & 51.5 & 0.63 \\
\hline 7 & {$\left[\mathrm{~N}_{22} \mathrm{~N}_{33} \mathrm{~N}_{64}\right] \mathrm{BF}_{4}$} & 330 & 557 & 51.3 & 0.64 & 8 & {$\left[\mathrm{~N}_{22} \mathrm{~N}_{33} \mathrm{~N}_{66}\right] \mathrm{BF}_{4}$} & 350 & 556 & 51.4 & 0.64 \\
\hline 9 & {$\left[\mathrm{~N}_{22} \mathrm{~N}_{33} \mathrm{~N}_{68}\right] \mathrm{BF}_{4}$} & 330 & 559 & 51.5 & 0.63 & 10 & {$\left[\mathrm{~N}_{22} \mathrm{~N}_{33} \mathrm{~N}_{610}\right] \mathrm{BF}_{4}$} & 300 & 557 & 51.3 & 0.64 \\
\hline 11 & {$\left[\mathrm{~N}_{22} \mathrm{~N}_{33} \mathrm{~N}_{63}\right]$ Ace } & 390 & 517 & 55.3 & 0.76 & 12 & {$\left[\mathrm{~N}_{22} \mathrm{~N}_{33} \mathrm{~N}_{64}\right]$ Ace } & 406 & 514 & 55.6 & 0.77 \\
\hline 13 & {$\left[\mathrm{~N}_{22} \mathrm{~N}_{33} \mathrm{~N}_{66}\right]$ Ace } & 420 & 517 & 55.3 & 0.76 & 14 & {$\left[\mathrm{~N}_{22} \mathrm{~N}_{33} \mathrm{~N}_{68}\right]$ Ace } & 350 & 514 & 55.7 & 0.77 \\
\hline 15 & {$\left[\mathrm{~N}_{22} \mathrm{~N}_{33} \mathrm{~N}_{610}\right]$ Ace } & 360 & 513 & 55.7 & 0.77 & 16 & {$\left[\mathrm{~N}_{22} \mathrm{~N}_{33} \mathrm{~N}_{61}\right] \mathrm{Tos}$} & 650 & 531 & 53.9 & 0.72 \\
\hline 17 & {$\left[\mathrm{~N}_{22} \mathrm{~N}_{33} \mathrm{~N}_{62}\right] \mathrm{Tos}$} & 740 & 579 & 49.4 & 0.58 & 18 & {$\left[\mathrm{~N}_{22} \mathrm{~N}_{33} \mathrm{~N}_{64}\right] \mathrm{Tos}$} & 750 & 565 & 50.6 & 0.61 \\
\hline 19 & {$\left[\mathrm{~N}_{22} \mathrm{~N}_{33} \mathrm{~N}_{66}\right] \mathrm{Tos}$} & 350 & 565 & 50.6 & 0.61 & 20 & {$\left[\mathrm{~N}_{22} \mathrm{~N}_{33} \mathrm{~N}_{68}\right] \mathrm{Tos}$} & 300 & 572 & 49.9 & 0.59 \\
\hline 21 & {$\left[\mathrm{~N}_{22} \mathrm{~N}_{33} \mathrm{~N}_{610}\right]$ Tos } & 450 & 611 & 46.8 & 0.50 & 22 & {$\left[\mathrm{~N}_{22} \mathrm{~N}_{33} \mathrm{~N}_{63}\right] \mathrm{Sac}$} & 520 & 573 & 49.9 & 0.59 \\
\hline 23 & {$\left[\mathrm{~N}_{22} \mathrm{~N}_{33} \mathrm{~N}_{64}\right] \mathrm{Sac}$} & 400 & 566 & 50.5 & 0.61 & 24 & {$\left[\mathrm{~N}_{22} \mathrm{~N}_{33} \mathrm{~N}_{66}\right] \mathrm{Sac}$} & 420 & 572 & 50.0 & 0.60 \\
\hline 25 & {$\left[\mathrm{~N}_{22} \mathrm{~N}_{33} \mathrm{~N}_{68}\right] \mathrm{Sac}$} & 350 & 573 & 49.9 & 0.59 & 26 & {$\left[\mathrm{~N}_{22} \mathrm{~N}_{33} \mathrm{~N}_{610}\right] \mathrm{Sac}$} & 360 & 574 & 49.8 & 0.59 \\
\hline 27 & {$\left[\mathrm{~N}_{11} \mathrm{~N}_{22} \mathrm{~N}_{44}\right]$ TFA } & 199 & 676 & 42.3 & 0.36 & 28 & {$\left[\mathrm{~N}_{11} \mathrm{~N}_{22} \mathrm{~N}_{44}\right] \mathrm{TfO}$} & 49 & 620 & 46.1 & 0.48 \\
\hline 29 & {$\left[\mathrm{~N}_{11} \mathrm{~N}_{22} \mathrm{~N}_{44}\right] \mathrm{Tf}_{2} \mathrm{~N}$} & 22 & 572 & 50.0 & 0.60 & 30 & {$\left[\mathrm{~N}_{22} \mathrm{~N}_{44} \mathrm{~N}_{66}\right] \mathrm{TFA}$} & 157 & 654 & 43.7 & 0.40 \\
\hline 31 & {$\left[\mathrm{~N}_{22} \mathrm{~N}_{44} \mathrm{~N}_{66}\right] \mathrm{TfO}$} & 637 & 598 & 46.8 & 0.53 & 32 & {$\left[\mathrm{~N}_{22} \mathrm{~N}_{44} \mathrm{~N}_{66}\right] \mathrm{Tf}_{2} \mathrm{~N}$} & 28 & 665 & 43.0 & 0.38 \\
\hline 33 & {$\left[\mathrm{~N}_{11} \mathrm{~N}_{22} \mathrm{~N}_{2 O 1,2 O 1}\right] \mathrm{Cl}$} & 164 & 640 & 44.7 & 0.43 & 34 & {$\left[\mathrm{~N}_{11} \mathrm{~N}_{22} \mathrm{~N}_{2 O 1,2 O 1}\right]$ TFA } & 311 & 634 & 45.1 & 0.44 \\
\hline 35 & {$\left[\mathrm{~N}_{11} \mathrm{~N}_{22} \mathrm{~N}_{2 O 1,2 O 1}\right] \mathrm{TfO}$} & 110 & 576 & 49.6 & 0.58 & 36 & {$\left[\mathrm{~N}_{11} \mathrm{~N}_{22} \mathrm{~N}_{2 O 1,2 \mathrm{Ol}}\right] \mathrm{Tf}_{2} \mathrm{~N}$} & 39 & 603 & 47.4 & 0.52 \\
\hline
\end{tabular}

${ }^{\text {a }}$ Spectra measured at $30^{\circ} \mathrm{C}$ (entries $\left.1-26\right), 25^{\circ} \mathrm{C}$ (entries $28,29,32$ and 36) and ambient temperature (entries $30,31,33-35$ ).

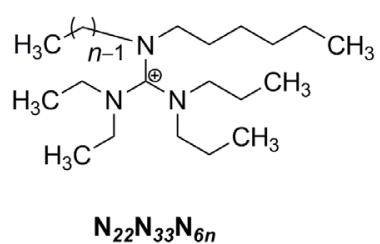

$(n=1,2,3,4,6,8,10)$<smiles>CCCCN(CCCC)[C@@H](N(C)C)N(CC)CC</smiles>

$\mathrm{N}_{11} \mathrm{~N}_{22} \mathrm{~N}_{44}$<smiles>CCCCCCN(CCCCCC)C(N(CC)CCCC)N(CC)CCCC</smiles>

$\mathrm{N}_{22} \mathrm{~N}_{44} \mathrm{~N}_{66}$<smiles>CCN(CC)C(N(C)C)N(CCOC)CCOC</smiles>

$\mathrm{N}_{11} \mathrm{~N}_{22} \mathrm{~N}_{201,201}$

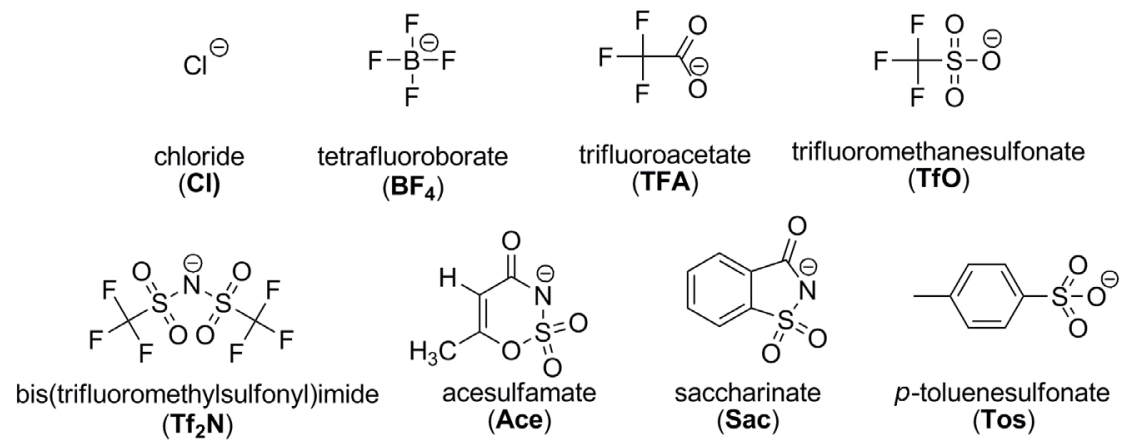

Fig. 2. Structures of cations and anions of guanidinium ILs investigated in this study.

in the sequence of chloride, saccharinate, tetrafluoroborate and acesulfamate; the acesulfamate series shows a polarity close to the polar HBD solvent methanol (mean value $E_{\mathrm{T}}^{\mathrm{N}}=0.77$ ), while the $\left[\mathrm{N}_{22} \mathrm{~N}_{33} \mathrm{~N}_{6 n}\right]-$ Sac, $-\mathrm{BF}_{4}$ and -Tos series are mainly in the range of other primary short-chain aliphatic alcohols. These findings suggest that the polarity properties of a given hexaalkylguanidinium RTIL series can be fixed in a quite narrow range by using the appropriate anion, and at the same time another desirable property can be varied by changing an alkyl substituent $\mathrm{R}$. In preceding communications $[15,16]$, some of us have shown that some physico-chemical properties of RTILs, such as density, viscosity and ionic conductivity, are fine-tunable by using the simple linear correlations derived from the developed Residual Volume Approach.

For the hexaalkylguanidinium ILs in group 2 (Table 1 , entries $27-36$ ), the $E_{\mathrm{T}}^{\mathrm{N}}$ values in general also 


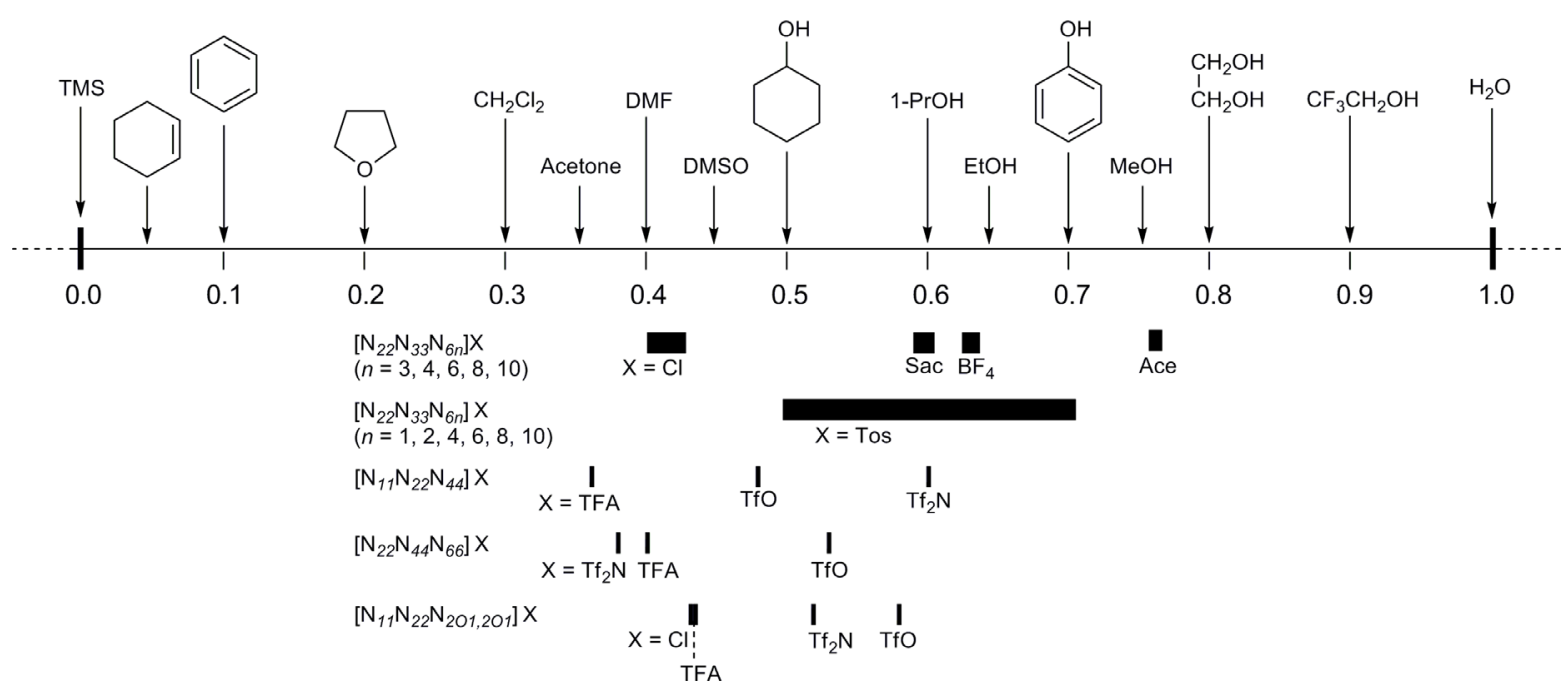

Fig. 3. Normalized solvent polarity scale $E_{\mathrm{T}}^{\mathrm{N}}$ according to ref. [21] with ordering of sixteen selected solvents and the inclusion of polarity data for the guanidinium RTILs in Table 1 , entries $1-36$.

appear to depend more on the anion than on the structural differences between the three sets of cations (Fig. 3). The chloride salt and the three trifluoroacetate salts $\left(E_{\mathrm{T}}^{\mathrm{N}}=0.36-0.44\right)$ appear in the polarity range of dipolar NHBD solvents such as acetone and $\mathrm{DMF}$, while the triflate salts $\left(E_{\mathrm{T}}^{\mathrm{N}}=0.48-0.58\right)$ and the bistriflimide salts with one exception $\left(E_{\mathrm{T}}^{\mathrm{N}}=0.38-\right.$ $0.60)$ are in the range which is covered by the tosylates $\left[\mathrm{N}_{22} \mathrm{~N}_{33} \mathrm{~N}_{6 n}\right]$ Tos and is also occupied by the lower aliphatic alcohols and phenol. The polarity values increase in the order $\mathrm{Cl}^{-}<\mathrm{TFA}^{-}<\mathrm{TfO}^{-}$which results from the combination of the order of decreasing nucleophilicity, hydrogen bonding ability and coordination strength. In a crystal structure analysis of a hexasubstituted guanidinium triflate, we have observed that the shortest non-bonding contacts of the triflate oxygen atoms are those with the central carbon atom and two $\mathrm{N}-\mathrm{C}^{\alpha}$ carbon atoms of the guanidinium function (3.1$3.2 \AA$, i. e. in the range of the sum of the $\mathrm{vdW}$ radii) [27]. It can be argued that the more nucleophilic anions coordinate more tightly with the guanidinium function, thereby reducing the ability of the latter to acidify the adjacent $\mathrm{C}-\mathrm{H}$ bonds. The hydrogen bond interactions between the cationic guanidinium part and the phenoxide oxygen atom thus become less effective, and the stabilization of the polar ground state of dye $\mathbf{1}$ is diminished, leading to a bathochromic shift of the absorption maximum of 1. According to these explanations, the triflimide ionic liquids are expected to be even more polar than those with the $\mathrm{Cl}^{-}, \mathrm{TFA}^{-}$, and $\mathrm{TfO}^{-}$anions.
Mass spectrometric studies have shown that the $\mathrm{Tf}_{2} \mathrm{~N}$ anion is by far the least interacting one in various ILforming salts [26]. Fig. 3 shows that $\left[\mathrm{N}_{11} \mathrm{~N}_{22} \mathrm{~N}_{44}\right] \mathrm{NTf}_{2}$ has indeed the highest polarity value, but unexpectedly this value drops below that of the trifluoroacetate for $\left[\mathrm{N}_{22} \mathrm{~N}_{44} \mathrm{~N}_{66}\right] \mathrm{NTf}_{2}$ and is slightly smaller than that of the triflate salt in $\left[\mathrm{N}_{11} \mathrm{~N}_{22} \mathrm{~N}_{2 O 1,2 O 1}\right] \mathrm{NTf}_{2}$.

Concerning the influence of the cation on the polarity, Fig. 3 shows that replacement of a dimethylamino group in the $\left[\left(\mathrm{NMe}_{2}\right)\left(\mathrm{NEt}_{2}\right)\left(\mathrm{NBu}_{2}\right) \mathrm{C}\right]^{+}$cation by a dihexylamino group, or of a dibutylamino by a bis(2-methoxyethyl)amino group, leads to a rather small increase of polarity for the TFA and TfO salts. For the three $\mathrm{Tf}_{2} \mathrm{~N}$ salts, it appears that the polarity, as expressed by the $E_{\mathrm{T}}^{\mathrm{N}}$ values, depends in a different manner on the structure of the cation. It also appears that, at least for the cation/anion combinations investigated here, the $\left[\mathrm{N}_{11} \mathrm{~N}_{22} \mathrm{~N}_{2 O 1,2 O 1}\right]$ cation, which incorporates two ether groups, controls the polarity somewhat more than the two hexaalkylguanidinium cations without these polar functions.

The results of our polarity studies using Reichardt's dye give the impression that the polarity of hexaalkylguanidinium-based ionic liquids is exceptionally sensitive to the nature of the anionic component in these salts. Data for other ILs, e. g. 1-alkyl-3methylimidazolium [23b, 23d] and 1-alkylpyridinium [23e], show a much smaller variation with the anion and do not display significant changes when the alkyl group is gradually changed in salts containing weakly 
Table 2. Absorption maximum $\left(\lambda_{\max }\right)$ and molar electronic transition energy $\left(E_{\mathrm{T}}\right)$ of dye $\mathbf{2}$ in hexaalkylguanidinium and imidazolium RTILs and in some organic solvents [24a].

\begin{tabular}{|c|c|c|c|c|}
\hline$\overline{\text { Entry }}$ & Ionic liquid & $\begin{array}{l}\mathrm{H}_{2} \mathrm{O}^{\mathrm{a}} \\
(\mathrm{ppm})\end{array}$ & $\begin{array}{l}\lambda_{\max } \\
(\mathrm{nm})\end{array}$ & $\begin{array}{c}E_{\mathrm{T}} \\
\left(\mathrm{kcal} \mathrm{mol}^{-1}\right)^{\mathrm{b}}\end{array}$ \\
\hline 1 & {$\left[\mathrm{~N}_{11} \mathrm{~N}_{22} \mathrm{~N}_{44}\right] \mathrm{TFA}$} & 199 & 610 & 46.9 \\
\hline 2 & {$\left[\mathrm{~N}_{11} \mathrm{~N}_{22} \mathrm{~N}_{44}\right] \mathrm{TfO}$} & 375 & 586 & 48.8 \\
\hline 3 & {$\left[\mathrm{~N}_{11} \mathrm{~N}_{22} \mathrm{~N}_{44}\right] \mathrm{Tf}_{2} \mathrm{~N}$} & 30 & 608 & 47.0 \\
\hline 4 & {$\left[\mathrm{~N}_{22} \mathrm{~N}_{44} \mathrm{~N}_{66}\right] \mathrm{TFA}$} & 157 & 604 & 47.3 \\
\hline 5 & {$\left[\mathrm{~N}_{22} \mathrm{~N}_{44} \mathrm{~N}_{66}\right] \mathrm{TfO}$} & 637 & 604 & 47.3 \\
\hline 6 & {$\left[\mathrm{~N}_{22} \mathrm{~N}_{44} \mathrm{~N}_{66}\right] \mathrm{Tf}_{2} \mathrm{~N}$} & 157 & 550 & 52.0 \\
\hline 7 & {$\left[\mathrm{~N}_{11} \mathrm{~N}_{22} \mathrm{~N}_{2 O 1,2 \mathrm{Ol}}\right] \mathrm{Cl}$} & 164 & 616 & 46.4 \\
\hline 8 & {$\left[\mathrm{~N}_{11} \mathrm{~N}_{22} \mathrm{~N}_{2 O 1,2 O 1}\right] \mathrm{TFA}$} & 311 & 648 & 44.1 \\
\hline 9 & {$\left[\mathrm{~N}_{11} \mathrm{~N}_{22} \mathrm{~N}_{2 O 1,2 O 1}\right] \mathrm{TfO}$} & 110 & 630 & 45.4 \\
\hline 10 & {$\left[\mathrm{~N}_{11} \mathrm{~N}_{22} \mathrm{~N}_{2 O 1,2 \mathrm{Ol}}\right] \mathrm{Tf}_{2} \mathrm{~N}$} & 20 & 540 & 52.9 \\
\hline 11 & {$[\mathrm{emim}] \mathrm{Tf}_{2} \mathrm{~N}^{\mathrm{c}}$} & 50 & 544 & 52.6 \\
\hline 12 & {$[\mathrm{bmim}] \mathrm{Tf}_{2} \mathrm{~N}^{\mathrm{d}}$} & 5371 & 548 & 52.2 \\
\hline 13 & $n$-hexane & & 466.2 & 61.3 \\
\hline 14 & tetrahydrofuran & & 520.6 & 54.9 \\
\hline 15 & dimethyl formamide & & 548.9 & 52.1 \\
\hline 16 & dimethyl sulfoxide & & 563.2 & 50.8 \\
\hline 17 & formamide & & 577.2 & 49.5 \\
\hline 18 & formamide/water $(1: 1)$ & & 597.4 & 47.9 \\
\hline
\end{tabular}

a Water content in the ionic liquid; ${ }^{b}$ calculated according to 3-methylimidazolium.

coordinating anions such as $\mathrm{TfO}^{-}$and $\mathrm{Tf}_{2} \mathrm{~N}^{-}$. As the polarity of a solvent is a macroscopic property which results from all specific and unspecific solvent/solute interactions, we do not try to give explanations at the molecular-microscopic level for all the observations made in this study. It must also be kept in mind that ionic liquids have structural and dynamic properties which are different from the classical molecular fluids, and which have just begun to be understood [28, 29].

The merocyanine-like dye $\mathbf{2}$ is known to display unusually large positive solvatochromism [24, 25]. However, to the best of our knowledge, it has not yet been used to establish a polarity scale of ionic liquids. In Table 2 , the long-wavelength absorption data $\left(\lambda_{\max }\right)$ and electronic transition energies $\left(E_{\mathrm{T}}\right)$ of $\mathbf{2}$ in some hexaalkylguanidinium and, for comparison, two 1,3dialkylimidazolium ILs are collected. Literature data for selected organic solvents are also included (data for a larger set of organic solvents can be found in ref. [24b]).

The data of the investigated ionic liquids can be divided in two groups. For four of the five bistriflimides (both guanidinium and imidazolium cations: entries $6,10-12)$, the dye has $\lambda_{\max }$ values in the range $540-550 \mathrm{~nm}\left(E_{\mathrm{T}}=52.9-52.0 \mathrm{kcal} \mathrm{mol}^{-1}\right)$, which puts these ILs in the neighborhood of DMF and dichloromethane $\left(\lambda_{\max }=535 \mathrm{~nm}\right)$. The remain- ing bistriflimide (entry 3) and the hexaalkylguanidinium chloride, trifluoroacetate and triflate salts give rise to considerable bathochromic shifts $\left(\lambda_{\max }=586-\right.$ $648 \mathrm{~nm}$ ), placing their polarity data in the range of formamide/water mixtures and far beyond. These high polarity characteristics and the wide range of values are not readily explained, the more so when a comparison is made with Nile Red, another positively solvatochromic probe. Nile Red also shows large bathochromic shifts when dissolved in increasingly polar media and is considered to be rather insensitive to hydrogen bond formation [30]. The $\lambda_{\max }$ values of this dye in a wide range of ionic liquids, based on 1-alkyl-3-methylimidazolium, pyrrolidinium, and tetraalkylammonium cations and with several different anions $\left(\mathrm{NO}_{2}^{-}, \mathrm{NO}_{3}^{-}, \mathrm{BF}_{4}^{-}, \mathrm{PF}_{6}^{-}, \mathrm{Tf}_{2} \mathrm{~N}^{-}, \mathrm{Tf}_{3} \mathrm{C}^{-}\right)$have been recorded [6a, 31, 32]. They were found, with very few exceptions, in a rather narrow range in the upper half of the polarity scale, with short-chain aliphatic alcohols and DMSO as the nearest neighbors. Due to the complete lack of data for other ionic liquids, the polarity data of the ILs shown in Table 2 are not amenable to a comparison. However, it should be noted that for a wide range of molecular solvents, an excellent correlation of the solvatochromic data of $\mathbf{2}$ with Kamlet and Taft's $\pi^{*}$ values has been found [24]. In turn, it has been reported that the $\pi^{*}$ values of several imidazolium- and pyrrolidinium-based ionic liquids are high in comparison with non-aqueous molecular solvents, and that ILs with $\mathrm{Tf}_{2} \mathrm{~N}$ anions give slightly lower values than salts with better coordinating anions [23b]. These observations qualitatively confirm our own observations.

\section{Conclusion}

In this study, experimental polarity parameters for a large number of hexaalkylguanidinium-based ionic liquids have been determined using two different solvatochromic probes, Reichardt's dye (1) and 5-dimethylamino-5'-nitro-2,2'-bithiophene (2). While the solvatochromic behavior of $\mathbf{1}$ is based to a major part on the interactions of the phenoxide oxygen atom with the solvent and is therefore very susceptible to hydrogen bond interactions, dye 2 senses the unspecific solvent/solute interactions. Given these differences, it is not surprising that the ionic liquids investigated occupy different regions of the two polarity scales. On Reichardt's $E_{\mathrm{T}}^{\mathrm{N}}$ scale, all ILs are in the range $0.36-0.77$. This is the typical range for 
Table 3. The influence of the water content on the longwavelength absorption $\left(\lambda_{\max }\right)$ of dye $\mathbf{1}$ in selected ionic liquids.

\begin{tabular}{lccc}
\hline Ionic liquid & $\mathrm{H}_{2} \mathrm{O}(\mathrm{ppm})$ & $\lambda_{\max }(\mathrm{nm})$ & $E_{\mathrm{T}}^{\mathrm{N}}$ \\
\hline$\left[\mathrm{N}_{11} \mathrm{~N}_{22} \mathrm{~N}_{2 O 1,2 O I}\right] \mathrm{Cl}$ & 164 & 640 & 0.43 \\
& 2611 & 640 & 0.43 \\
{$\left[\mathrm{~N}_{11} \mathrm{~N}_{22} \mathrm{~N}_{2 O 1,2 O 1}\right]$ TFA } & 4890 & 640 & 0.43 \\
& 311 & 634 & 0.44 \\
{$\left[\mathrm{~N}_{11} \mathrm{~N}_{22} \mathrm{~N}_{2 O 1,2 O 1}\right]$ TfO } & 1818 & 648 & 0.41 \\
& 3472 & 648 & 0.41 \\
{$\left[\mathrm{~N}_{11} \mathrm{~N}_{22} \mathrm{~N}_{44}\right]$ TFA } & 110 & 576 & 0.58 \\
& 1828 & 574 & 0.59 \\
{$\left[\mathrm{~N}_{11} \mathrm{~N}_{22} \mathrm{~N}_{44}\right] \mathrm{Tf}_{2} \mathrm{~N}$} & 3003 & 578 & 0.58 \\
& 199 & 676 & 0.36 \\
& 2478 & 670 & 0.37 \\
& 5636 & 652 & 0.41 \\
& 22 & 572 & 0.60 \\
& 1113 & 571 & 0.60 \\
& 1448 & 572 & 0.60 \\
\hline
\end{tabular}

ionic liquids in general, although members of individual cation-derived classes are usually grouped together more closely. On the polarity scale based on $\mathbf{2}$, the hexaalkylguanidinium ILs with chloride, trifluoroacetate and triflate anions are found at the upper end, while the bistriflimide salts of both hexaalkylguanidinium (with one exception) and imidazolium ILs are in the middle of this scale. It is noteworthy that the polarity data of hexaalkylguanidinium-based ionic liquids on both scales are susceptible to the nature of the anion and also to the cation/anion combination to a much greater extent than reported for other common ionic liquids. The reasons are not readily evident and should be clarified in future investigations.

\section{Experimental Section}

The synthesis and characterization of the guanidinium salts investigated here have been reported elsewhere (Table 1, entries 1-26: ref. [16]; entries 27-36: ref. [13]).

\section{Polarity measurements}

Spectral measurements were carried out on Perkin-Elmer UV/Vis Lambda 14 (Table 1, entries 1-26) and Analytik Jena Specord 50 spectrometers (Table 1, entries $27-36$ ). The concentrations of dye $\mathbf{1}$ or $\mathbf{2}$ in the solutions were in the range $10^{-5}$ to $10^{-4} \mathrm{M}$. Before application, the ionic liquid was kept at $70{ }^{\circ} \mathrm{C} / 0.1 \mathrm{mbar}$ for $4-7 \mathrm{~h}$, and prior to a measurement, the water content was determined by Karl-Fischer titration with a Metrohm $831 \mathrm{KF}$ coulometer. Almost all of the investigated ionic liquids were colorless or nearly so. In some cases, short treatment of the ionic liquid dissolved in dichloromethane with alumina 90 (active, neutral; Merck) was used to remove trace amounts of colored impurities.

The samples for UV/Vis measurements were prepared and handled without taking additional precautions against the absorption of water from the laboratory atmosphere. In order to test the influence of a varying content of water in the samples on the long-wavelength absorption of Reichardt's dye (1), several samples (Table 1, entries 27 -36) were submitted to subsequent measurements (UV/Vis and KF titration) after having the samples exposed to the laboratory atmosphere for some time. Selected results are given in Table 3.

\section{Acknowledgements}

This work was supported financially by the Bundesministerium für Bildung und Forschung (BMBF), project "Novel Ionic Liquids as Innovative Reaction Media for Technical Organic Chemistry". We thank Professors C. Reichardt and H. Hartmann for providing us with dyes $\mathbf{1}$ and $\mathbf{2}$, respectively.
[1] P. Wasserscheid, T. Welton (Eds.), Ionic Liquids in Synthesis, $2^{\text {nd }}$ ed., Wiley-VCH, Weinheim, 2007.

[2] a) V. I. Pârvulescu, C. Hardacre, Chem. Rev. 2007, 107, 2615-2665; b) P. J. Dyson, T. J. Geldbach, Metal Catalysed Reactions in Ionic Liquids, Springer, Dordrecht 2006; c) T. Welton, Coord. Chem. Rev. 2004, 248, 2459-2477; d) R. Sheldon, Chem. Commun. 2001, 2399-2407; e) F. V. Rantwijk, R. A. Sheldon, Chem. Rev. 2007, 107, 2757-2785.

[3] a) P. Hapiot, C. Lagrost, Chem. Rev. 2008, 108, 2238 2264; b) D. S. Silvester, R. G. Compton, Z. Phys. Chem. 2006, 220, $1247-1274$.

[4] a) D. Shi, N. Pootrakulchote, R. Li, J. Guo, Y. Wang, S. M. Zakeeruddin, M. Grätzel, P. Wang, J. Phys. Chem. C 2008, 112, 17046 - 17050; b) D. Shi, Y. Cao, N. Pootrakulchote, Z. Yi, M. Xu, S. M. Zakeeruddin,
M. Grätzel, P. Wang, J. Phys. Chem. C 2008, 112, 17478 -17485; Y. Bai, Y. Cao, J. Zhang, M. Wang, R. Li, P. Wang, S. M. Zakeeruddin, M. Grätzel, Nature Materials 2008, 7, 626-630.

[5] P. Sun, D. W. Armstrong, Anal. Chim. Acta 2010, 661, $1-16$.

[6] a) C. F. Poole, J. Chromatogr. A 2004, 1037, 49-82; b) S. K. Poole, P.H. Shetty, C.F. Poole, Anal. Chim. Acta 1989, 218, 241 - 264; c) P. H. Shetty, P. J. Youngberg, B. R. Kersten, C. F. Poole, J. Chromatogr. 1987, $411,61-79$.

[7] a) P. S. Kulkarni, L.C. Branco, J. G. Crespo, M. C. Nunes, A. Raymundo, C. A. M. Afonso, Chem. Eur. J. 2007, 13, 8478 -8488; b) P. S. Kulkarni, L. C. Branco, J. G. Crespo, C. A. M. Afonso, Chem. Eur. J. 2007, 13, $8470-8477$. 
[8] S. Zhang, N. Sun, X. He, X. Lu, X. Zhang, J. Phys. Chem. Ref. Data 2006, 35, $1475-1517$.

[9] W. Kantlehner, E. Haug, W. W. Mergen, P. Speh, T. Maier, J. J. Kapassakalidis, H.-J. Bräuner, H. Hagen, Liebigs Ann. Chem. 1984, $108-126$.

[10] N.M. M. Mateus, L.C. Branco, N.M.T. Lourenço, C. A. M. Afonso, Green Chem. 2003, 5, 347-352.

[11] Y. Gao, S. W. Arritt, B. Twamley, J. M. Shreeve, Inorg. Chem. 2005, 44, $1704-1712$.

[12] H.-F. Duan, X. Guo, S.-H. Li, Y.-J. Lin, S.-B. Zhang, H.-B. Xie, Chinese J. Org. Chem. 2006, 26, 13351343.

[13] H. Kunkel, G. Maas, Eur. J. Org. Chem. 2007, $3746-$ 3757.

[14] S. Fang, L. Yang, C. Wei, C. Jiang, K. Tachibana, K. Kamijima, Electrochim. Acta 2009, 54, 1752 1756.

[15] a) M. G. Bogdanov, W. Kantlehner, Z. Naturforsch. 2009, 64b, 215-222; b) M. G. Bogdanov, B. Iliev, W. Kantlehner, Z. Naturforsch. 2009, 64b, 756-764.

[16] M. G. Bogdanov, D. Petkova, S. Hristeva, I. Svinyarov, W. Kantlehner, Z. Naturforsch. 2010, 65b, 37-48.

[17] For a definition of the term 'polarity', see: IUPAC Compendium of Chemical Terminology, $2^{\text {nd }}$ ed., 1997.

[18] C. Reichardt, Solvents and Solvent Effects in Organic Chemistry, $2^{\text {nd }}$ ed., VCH, Weinheim, 1988.

[19] a) $E_{\mathrm{T}}(30)$ : C. Reichardt, Chem. Rev. 1994, 94, 2319 2358 ; b) $E_{\mathrm{T}}^{\mathrm{N}}$ : C. Reichardt, E. Harbusch-Görnert, Liebigs Ann. Chem. 1983, 721 - 743.

[20] a) M. J. Kamlet, J. L. Abboud, R. W. Taft, J. Am. Chem. Soc. 1977, 99, 6027-6038; b) M. J. Kamlet, J.-L. M. Abboud, M. H. Abraham, R.W. Taft, J. Org. Chem. 1983, 48, $2877-2887$.

[21] C. Reichardt, Green Chem. 2005, 7, 339-351.
[22] B. R. Mellein, S. N. V. K. Aki, R. L. Ladewski, J.F. Brennecke, J. Phys. Chem. B 2008, 111, 131-138.

[23] a) S. N. Baker, G. A. Baker, F.V. Bright, Green Chem. 2002, 3, 165-169; b) L. Crowhurst, P.R. Mawdsley, J. M. Perez-Arlandis, P. A. Salter, T. Welton, Phys. Chem. Chem. Phys. 2003, 5, 2790-2794; c) A. Oehlke, K. Hofmann, S. Spange, New J. Chem. 2006, 30, 533-536; d) H. Tokuda, S. Tsuzuki, Md. A. B.H. Susan, K. Hayamizu, M. Watanabe, J. Phys. Chem. B 2006, 110, 19593 - 19600; e) J.-M. Lee, S. Ruckes, J. M. Prausnitz, J. Phys. Chem. B 2008, 112, $1373-1476$.

[24] a) F. Effenberger, F. Würthner, Angew. Chem. 1993, 105, 742 - 744; Angew. Chem., Int. Ed. Engl. 1993, 21, $719-721$; b) F. Effenberger, F. Würthner, F. Steybe, $J$. Org. Chem. 1995, 60, $2082-2091$.

[25] H. Hartmann, K. Eckert, A. Schröder, Angew. Chem. 2000, 112, 567-569; Angew. Chem. Int. Ed. 2000, 39, $556-558$.

[26] R. Bini, O. Bortolini, C. Chiappe, D. Pieraccini, T. Siciliano, J. Phys. Chem. B 2007, 111, 598-604.

[27] H. Kunkel, Dissertation, University of Ulm, Ulm (Germany) 2008.

[28] C. Chiappe, Monatsh. Chem. 2007, 138, 1035 - 1043.

[29] H. Weingärtner, Angew. Chem. 2008, 120, 644-682; Angew. Chem. Int. Ed. 2008, 47, 654-670.

[30] J. F. Deye, T. A. Berger, A. G. Anderson, Anal. Chem. 1990, 62, 615-622.

[31] A. J. Carmichael, K. R. Seddon, J. Phys. Org. Chem. 2000, 13, $591-595$.

[32] H. Jin, B. O'Hare, J. Dong, S. Arzhantsev, G. A. Baker, J. F. Wishart, A. J. Benesi, M. Maroncelli, J. Phys. Chem. B 2008, 112, 81-92. 